\title{
Whither with the Will? : A Phenomenological Critique of Free Will, Ethicality and the Idea of the Animal
}

\author{
Soham Ganguly \\ MPhil student of the English Department of the University of Calcutta. ORCID: \\ http://orcid.org/oooo-ooo2-3928-5838. Email: sohamggoo7@gmail.com
}

Received May 29, 2016; Revised July 24, 2016; Accepted July 30, 2016; Published August 18, 2016

\begin{abstract}
Free will, which directly pertains to ethical choices, has for long been a point of contention in the spheres of philosophy and the sciences, the latter putting forth chiefly a naturalist account of it, a thinking apparatus which, permeated by evolutionary discourse, privileges the human organism over the non-human by virtue of, among other things, a fundamental epistemic capacity to form conceptions beyond only the 'first-order', concerns of the present. In counterpoint to such an account, this paper posits an alternative, phenomenological account of the human subject as well as the body, founded upon spatio-temporality, and examines its ramifications.
\end{abstract}

Keywords: phenomenology, temporality, free will, ethicality, animal, naturalism

The possibility or impossibility of free will, and consequently the ethical imperatives placed upon the individual based upon the mediation of their desires and inclinations by virtue of the choices they happen to make has been a conundrum for thinkers and has undergone variegated interpretations for centuries. Indeed, the notion of the faculty of making choices is inextricably tied to that of the discursive structures which inform and punctuate how the subject may posit themselves amidst the intersectionality of ideological meshes in a socio-anthropogenic framework which harbours an Other in the discourse of the animal.

Ethicality, rooted in free will, which has suitably been referred to as distinct from a deontological register in the context of the will and the choices of an individual, which must center around the "face-to-face encounter" spectrum of ethical anxieties in a phenomenological sense, and it is here that it would seem, lies the lacuna of the animal's Otherness, in that it is bereft either of a correlative 'Face,' the phenomenological, gestural, eidetic envisagement (Kant, 1901), or, consequently of entrance into the "metaphysical," relationship thereof which is irreducible to the strata of intended representation on account of the ramifications brought on by time upon the essence of the face-to-face experientiality -

The role Kant attributed to sensible experience in the domain of the understanding belongs in metaphysics to interhuman relations. It is from moral relationships that every metaphysical affirmation takes on a "spiritual" meaning, is purified of everything with

(c) AesthetixMS 2016. This Open Access article is published under a Creative Commons Attribution Non-Commercial 4.0 International License (http://creativecommons.org/licenses/by-nc/4.o/), which permits non-commercial re-use, distribution, and reproduction in any medium, provided the original work is properly cited. For citation use the DOI. For commercial re-use, please contact editor@rupkatha.com. 
which an imagination captive of things and victim of participation charges our concepts (Levinas, 1969, p.97).

But such an analysis of the ethical kernel inevitably brings to the fore the very anxieties which underpin the variegated reception of the presence or absence of free will in humans, treating us instead to the notion of there being certain kinds of freedom "worth wanting," and "compatible with determinism", and thus leaving us with only a frugal window of freedom, for "if there is indeterminacy in free will, on my view, it must come somewhere between the input and the output" (Kane, 1996, p.39). Does this betray an anxiety of anthropocentric representation in the face of the discourse of socio-ethical possibles charting the trajectory of the very representation of the human subject, which endeavours to escape the same effacement which it rather hegemonically accords even in naturalistic modes to the animal Other in order to sustain itself and shape its paradigms?

The shape of such a concept of the will leads to its conception within a sphere of limitations of perception and likewise, of the very ability to apprehend phenomenal structures, and the effacement of the animal in what is discursively conceived as the singularly human with respect to possibilities of ethical rendezvous may be traced to such a naturalistic, deterministic discourse, privileging perpetually the capacity of the human to evolutionarily have become a "long distance knower" (Dennett, 2003, p.44), as opposed to being merely chained to the immediacy of percept, desire, and, with miniscule indeterminacy, decision.

The naturalistic perception of the way in which free will works is consequently tied up with the idea that it "seeks to articulate just what it is that makes such beings 'human' according to a certain criterion - or self-understanding - of genuine personhood that sets them apart both from non-human animals and also from those among their conspecifics who fall short of humanity in that regard" (Norris, 2016, p.4). This is momentously achieved because "many animals appear to have the capacity for [. . . 'first order desires,' [. . . which are simply desires to do or not to do one thing or another. No animal other than man, however, appears to have a capacity for reflective self-evaluation that is manifested in the formation of second-order desires" (Frankfurt, 1971, p.8). On a simpler scale, one may go as far as to perceive free will as 'a power of acting or of not acting, according to the determination of the will," (Hume, 1937, p.163). Here, we may endeavour to understand personhood in the Kantian sense as well, as a principle obtained a priori, just as his moral framework is, an amalgam of the exertion and awareness of dignity and autonomy, with the attendant moral scope of choosing between right and wrong (Allison, 2011, p.62). But the sense of knowing things or possibilities at 'a distance,' in the future, beyond what is merely the present ground of experience, involves the possibility of formulations of such secondorder desires as its functional manifestation, as opposed to first-order desires which are summed up by Frankfurt by the phrase, " $A$ wants to want to $X$ " $(1971$, p.6), therefore building upon the usage of the gap or window provided betwixt desires and their eventual direction for the instrumentalization of the will. We may, by this minimalist account, extend the view of the animal as one devoid of full existential agency in the facets of deliberations upon a tangible past or even with a mind that can contemplate upon directed courses of action constructed upon any binding framework of moral sensibilities. Indeed, it is said of the faculty of animality from a physicalist standpoint that it primarily bases the locus of its actions around a "Need-to-know," basis for, "in general, nature operates on a version of the Need to Know Principle [. . .] Bison don't need to know that they are ungulates within the class Mammalia-there is nothing they could do with that information, being bison; the Brazilians didn't (yet) need to know much about the larger environment of which their intimately known jungle environment formed a part, but the 
Brazilians, being human beings, could almost effortlessly extend their epistemic horizons as soon as they needed to know" (Dennett, 2003, p.49).

Even earlier on, the animal constituted the hinterground of the inscription of the notionally Promethean discourse of the distinctly human, for it was deemed singular only for humans, in counterpoint to the faculty of the animal qua animal, to contemplate the future and thus, in abstraction, transcend the present-

"More highly potentialized consciousness, this abstract reflection of everything intuitive in the non-intuitive concepts of reason is the only thing that gives people the circumspection that so completely distinguishes their consciousness from that of animals and which makes their stay on earth turn out so differently from that of their irrational brothers. People surpass animals as much in power as in suffering. Animals live only in the present; humans, meanwhile, live simultaneously in the future and the past. Animals satisfy their momentary needs; people use ingenious arrangements to provide for the future, even for times they will never experience. Animals are completely at the mercy both of momentary impressions and the effects of intuitive motives; people are determined by abstract concepts independent of the present moment. As a result, people can carry out considered plans and act on maxims without reference to the circumstances and contingent impressions of the moment." (Schopenhauer, 1966, p.261).

The specious present can, however, serve as a counter-anthropo-chronometrism in that it is held to be "the prototype of all conceived times [. . .] the short duration of which we are immediately and incessantly sensible" (James, 1950, p.192). Considered in this light, the Kantian (1901) notions of delimited pluralism in spatiotemporality are in order:

"Space is no discursive [. . .] general conception of the relations of things, but a pure intuition. For, in the first place, we can only represent to ourselves one space, and, when we talk of divers spaces, we mean only parts of one and the same space. Moreover, these parts cannot antecede this one all-embracing space, as the component parts from which the aggregate can be made up, but can be cogitated only as existing in it. Space is essentially one, and multiplicity in it, consequently the general notion of spaces, of this or that space, depends solely upon limitations. Hence it follows that an a priori intuition (which is not empirical) lies at the root of all our conceptions of space." (p.52-53).

By that same token, limitations pertinent to the immediacy of intuition become the basis of temporal perception:

"The infinity of time signifies nothing more than that every determined quantity of time is possible only through limitations of one time lying at the foundation. Consequently, the original representation, time, must be given as unlimited. But as the determinate representation [. . . ] can only be obtained by limitation, the complete representation of time must not be furnished by means of conceptions, for these contain only partial representations. Conceptions, on the contrary, must have immediate intuition for their basis." (Kant, 1901, p.59).

This, therefore necessitates the emergence of a framework that can readily apprehend, readily intuit, and accommodate the immediacy of ideation as well as limit such ontological experience within a non-thetic mode, which, by Webber's (2011) interpretation may be considered, in its 
primacy, analogous to the foregrounding of a somato-proprioceptic mould in order to answer to the demands placed upon the cognitive apparatus-

"In the first place, we cannot think of the kinaesthetic and proprioceptive system as gaining knowledge of truths about the condition of a body which leaves the question of the identity of the body open [. . . ] an idea of a world of objects and phenomena which can be perceived but which are not dependent on being perceived for their existencemust be able to think of his perception of the world as being simultaneously due to his position in the world, and to the condition of the world at that position. The very idea of a perceivable, objective, spatial world brings with it the idea of the subject as being in the world, with the course of his perceptions due to his changing position in the world and to the more or less stable way the world is. The idea that there is an objective world and the idea that the subject is somewhere cannot be separated, and where he is is given by what he can perceive." (Evans, 1982, p.220-21).

This leads us to court the notion, therefore, of the bodied, phenomenological apprehension of temporality.

We may, hence, bring ourselves to understand how the very faculty of time, which was thought to be in counterpoint to the disposition of animalistic cogitations when it came to those of the 'human', thus bringing them onto the selfsame intuitive stratum of phenomena, which must, hence, fail to encourage an a priori Kantian construct of the human deontological modus of the intrinsic ethicality of deeds. As Kant writes in The Critique of Practical Reason- "We then see how it does not involve any contradiction to assert, on the one hand, that the will, in the phenomenal sphere - in visible action - is necessarily obedient to the law of nature, and, in so far, not free; and, on the other hand, that, as belonging to a thing in itself, it is not subject to that law, and, accordingly, is free." (1956, xx). Our judgment must, therefore, proceed from such a stratum as is dessicated and bereft of apodeictic certitude, or any plenary, inherent, ethico-normativist predilection. We are thrust into the realm of the phenomenon itself, from which we are to trace our ethical kernel, just as the discursive structures of the animal posit to us. Our situation in the specious present, a sliver of the intuiting self procured by the limitations placed upon us by the immediacy of conception, be it for space or for time, must situate us in the very midst of the world of phenomenal possibles of the For-Itself from which we can judge the extent of the Freedom of the will. Our judgment is to be founded upon appearances of phenomena themselves:

"Essence, as the principle of the series, is definitely only the concatenation of appearances; that is, itself an appearance [...] The phenomenal being manifests itself; it manifests its essence as well as its existence, and it is nothing but the well connected series of its manifestations." (Sartre, 1956, p. xvi).

Negation causes distance, it furnishes us with the split between the Being-in-Itself and the BeingFor-Itself, and yet is, in turn, the relation between them, and the same goes for human reality, distances brought about by the entrance of negation into Being, be it cogitative or perceptual, also functioning as the manner of relation between them-

"We will willingly admit with Heidegger that "human reality" is "remote-from-itself;" that is, that it rises in the world as that which creates distances and at the same time causes them to be removed (entfernend). But this remoteness-from-self, even if it is the necessary condition in order that there may be remoteness in general, envelops remoteness in itself as the negative structure which must be surmounted. It will be useless to attempt to reduce distance to the simple result of a measurement. [. . .] Negation is the cement which 
realizes this unity. It defines precisely the immediate relation which connects these two points and which presents them to intuition as the indissoluble unity of the distance." (Sartre, 1956, p.325).

The For-Itself's relation of negation with the In-Itself makes it strive always to be what it is not and not be what it is, and it is because of that that it must formulate projects for itself to keep up the relation of negation, necessitating its exertions of will and composing for itself its own continual passage through phenomenal reality.

The world of the For-Itself is one in which there are only appearances, wherein each appearance is supported only by its own being, rather than having anything, so to say, behind it. This gives us a field of percepts and interactive elements where we can perceive, thus, insofar as we are constituted, made possible and also consequently held to be integrally limited by the body, and it is from this groundwork of the primacy of the body when it comes to relations with percepts that our consciousness must thus be directed towards the Other. The lucid distinction betwixt the Being-in-Itself and the Being-For-Itself is problematised by the Body as opposed to the general Facticity, considering that the For-Itself's inherent conatus of being what it is not and not being what it is must have the concept of the Body wedged in between these two, inducing the nonlinearity of their schism, bringing the precognitive, pre-reflective strata to interact with the domains of the distilled For-Itself in its Facticity, perceived by Sartre (1956), as a general limitation or mitigation posited against the freedom of wishes and representation-

"We are free when the final term by which we make known to ourselves what we are is an end; that is, not a real existent like that which in the supposition which we have made could fulfill our wish, but an object which does not yet exist. But consequently this end can be transcendent only if it is separated from us at the same time that it is accessible. Only an ensemble of real existents can separate us from this end-in the same way that this end can be conceived only as a state to-come of the real existents which separate me from it. It is nothing but the outline of an order of existents -that is, a series of dispositions to be assumed by existents on the foundation of their actual relations. By the internal negation, in fact, the for-itself illuminates the existents in their mutual relations by means of the end which it posits, and it projects this end in terms of the determinations which it apprehends in the existent." (p. 412).

This brings us to the veritable commingling of the bodily instrumentalization of the world with the layers of cogitational and ideational functionality. This is because, as we may derive from Kant's (1901) ratiocination, "intuition with us never can be other than sensuous, that is, it contains only the mode in which we are affected by objects" (p.58). Whereas we discover that "the faculty of thinking the object of sensuous intuition is the understanding. Neither of these faculties has a preference over the other" (p.61). We are led to the notion, consequentially, that "without the sensuous faculty no object would be given to us, and without the understanding no object would be thought" (p.61). The two faculties are seen to be inextricably tied to each other, for "thoughts without content are void; intuitions without conceptions, blind" (p.61).

It is this bind that brings Merleau-Ponty's (1968) conception of the Body into the equation, for while consciousness may be directed at phenomena-

"I can therefore take my place, through the medium of my body as the potential source of a certain number of familiar actions, in my environment conceived as a set of manipulanda and without, moreover, envisaging my body or my surrounding as objects in 
the Kantian sense, that is, as systems of qualities linked by some intelligible law, as transparent entities, free from any attachment to a specific place or time, and ready to be named or at least pointed out. There is my arm seen as sustaining familiar acts, my body as giving rise to determinate action having a field or scope known to me in advance, [...] the world as a pure spectacle into which I am not absorbed [. . .] even though it cannot be conveyed by a description or even by the mute reference of a gesture." (p. 274).

Furthermore, in his conception of space, Merleau-Ponty (1968) incorporates the conditions of bodily space, resultantly, so as to aver that:

"When I say that an object is on a table, I always mentally put myself either in the table or in the object, and I apply to them a category which theoretically fits the relationship of my body to external objects. Stripped of this anthropological association, the word on is indistinguishable from the word 'under' or the word 'beside'. Even if the universal form of space is that without which there would be for us no bodily space, it is not that by which there is one. Even if the form is not the setting in which, but the means whereby the content is posited, it is not the sufficient means of this act of positing as far as bodily space is concerned, and to this extent the bodily content remains, in relation to it, something opaque, fortuitous and unintelligible." (p.319).

The locus of directed consciousness is thus subject immensely to the integration of the Body, bridging the world of "brute existents" (Heidegger, 1962), and that of the For-Itself's "projects", both immediate and distant, and hence, again, according to Merleau-Ponty, (1968):

"But can we pretend to discover no distinctive meaning in the words 'on', 'under', 'beside', or in the dimensions of orientated space? Even if analysis discovers in all these relationships the universal relation of externality, the self-evidentness of top and bottom, right and left, for the person who has his being in space, [. . .] The relationships between the two spaces would therefore be as follows: as soon as I try to posit bodily space or bring out its meaning I find nothing in it but intelligible space. But at the same time this intelligible space is not extracted from orientated space, it is merely its explicit expression, and, when separated from that root has no meaning whatsoever. The truth is that homogeneous space can convey the meaning of orientated space only because it is from the latter that it has received that meaning. In so far as the content can be really subsumed under the form and can appear as the content of that form, it is because the form is accessible only through the content. Bodily space can really become a fragment of objective space only if within its individuality as bodily space it contains the dialectical ferment to transform it into universal space [. . .] the point-horizon structure is the foundation of space. The horizon or background would not extend beyond the figure or round about it, unless they partook of the same kind of being as the figure, and unless they could be converted into points by a transference of the gaze." (p. 351).

The project of a certain For-Itself, when considered in this light, is seen to be the totality of the outcomes of both its manifestations in the fields of space, and time as well, because the interpretation of temporality must occupy a central point of contention in the counter-discourse of the distinctly human by virtue of pitting the layers of the human with those of the corporeal as opposed to the wholly ideational, the bodied, the incessant grappling with the 'blind' animality latent within the physicalist account of the multicellular, the embodied encounters with 'bruteexistence'. Our own temporalization is the causal factor in the ethical relations that are forged- 
"I do not form a mental picture of my day, it weighs upon me with all its weight, it is still there, and though I may not recall any detail of it, I have the impending power to do so, I still 'have it in hand' [. . .] my world is carried forward by lines of intentionality which trace out in advance at least the style of what is to come (although we are always on the watch, perhaps to the day of our death, for the appearance of something else)." (MerleauPonty, 1968, p.366).

As Merleau-Ponty (1968), further elucidates, our own measure of traversing the domain of time is therefore in a bodied manner of progression by virtue of "protentions and retentions," (p.352) which are "the intentionalities which anchor me to an environment. They do not run from a central $I$, but from my perceptual field itself, so to speak, which draws along in its wake its own horizon of retentions, and bites into the future with its protections" (p.352).

And this is the point from which ethicality must spring forth, a wholly phenomenal plane charted by the insistence of the body:

"The corporeity of the will must be understood on the basis of this ambiguity of voluntary power, exposing itself to the others in its centripetal movement of egoism. The body is its ontological regime, and not an object. The body [. . . ] conveys the entry of the I into the calculations of the Other." (Levinas, 1969, p.202).

This becomes clearer in the exposition of the idea of what constitutes our goodness, our ethical bridge with the Other via the Face, because "Goodness consists in taking up a position in being such that the Other counts more than myself. Goodness thus involves the possibility for the I that is exposed to the alienation of its powers by death to not be for death" (Levinas, 1969, p.137); thus the For-Itself must temporalize itself in the interests of the Other as opposed to merely its own temporalization, must be 'for the Other,' rather than merely direct its conscious will towards a perpetual temporal progression of being what it is not and not being what it is until, as Sartre (1956) says, "eternity," which "changes us into ourselves," should make it a plenary Being-in-Itself, and render it phenomenally homogeneous with the Past. The ethical 'good', according to Moore (1903), cannot be likened to "Hedonistic attainment," or any derived from a "naturalistic fallacy," a broad idea including the notion that ethical goodness ultimately supervenes upon a tangible base, either utilitarian or otherwise, for one may inquire and infer that:

"Is there any sense in which a thing can be an ultimate rational end for one person and not for another? By ultimate must be meant at least that the end is good-in-itself- good in our undefinable(my emphasis) sense; and by rational, at least, that it is truly good. That a thing should be an ultimate rational end means, then, that it is truly good in itself; and that it is truly good in itself means that it is a part of Universal Good [. . .] the Egoist's happiness must either be good in itself, and so a part of Universal Good, or else it cannot be good in itself at all: there is no escaping this dilemma." (p. 94).

We are hence led to the idea of the inexplicable good, which is not derived from statements of facts whether it be in relation to a naturalistic, empirical or even calculably epistemic basis. Both the freedom of our will, and our ethics, must involve encounters on the level of phenomenal upsurges and appearances as opposed to any frame of ethicality hinged to a narrow window amidst a physicalist framework to permit and perpetuate deontological epistemic ethico-legal structures. 
It is with this end in mind, hence, that we are led to seek the foci of ethicality in the incidence of the Other, moreover, demanding the presence of the Other from which the "Face-toface relationship," must stem, doubly bringing us to the contemplation of a framework where proximity of perception, embodied, plays a major role in the bringing forth of agency-regard towards the being of the Other, for "sometimes, persons want to escape the ethical pressure of the choice they face concerning agency-regard. Yet they cannot escape the ethical pressure except by escaping the choice itself, and they cannot escape the choice so long as they recognize other persons as such. This may lead-and historically has led-some persons to deny the personhood of other persons" (Rovane, 1998, p.162), and the same may be true of animals. A deflation of the spatiotemporal supremacy asserted over the body of notions that constitute the image of what it is to be animal as distinct from the signification of humanity, therefore, leads us, in its consequential ramifications, to the heart of the problem of the ontological positionality of the human considered in relation to the animal-

"In what sense of the neighbor [. . . ] should I say that I am close or near to the animal and that I am (following) it, and in what type or order of pressure? Being-with it in the sense of being-close-to-it? Being-alongside-it? Being-after-it? Being-after-it in the sense of the hunt, training, or taming, or being-after-it in the sense of a succession or inheritance? In all cases, if I am (following) after it, the animal therefore comes before me, earlier than me (früher is Kant's word regarding the animal [...]). The animal is there before me, there close to me, there in front of me-I who am (following) after it. And also, therefore, since it is before me, it is behind me. It surrounds me. And from the vantage of this being-therebefore-me it can allow itself to be looked at, [. . .] it can look at me." (Derrida, 2016, p.16).

The perceptive phenomenal apparatus can only derive from the location of the conscious individual within the seat of embodiment which serves as the originary site for the projects of its For-Itself-

"For the question is, how does the soul know this space, its own body's, which it extends toward things, this primary here from which all the there's will come? This space [. . .] is the place of the body the soul calls "mine," a place the soul inhabits. [. . .] The soul thinks with reference to the body, not with reference to itself, and space, or exterior distance, is stipulated as well within the natural pact that unites them." (Merleau-Ponty, 1964, p.229).

Thus, this necessitates conceiving of a broader concept of the freedom of the will, and the ontoepistemic limits which are observed to comprise a temporal root of phenomenological coexistence of the human and the animal, if we are yet to go by that distinction, inevitably problematizes the denial of the Face to the animal. Ethicality, a relation which may be pondered in terms of the proximity of the human to the animal in the face-to-face encounter, shall, in turn call upon a wider spectrum of free will to address it, for ethical choices, of themselves, may be thought to proceed from a position considerably less deterministic than that of the physicalist.

\section{References}

Allison, Henry (2011). Kant's Groundwork for the Metaphysics of Morals: A Commentary. Oxford: Oxford University Press

Dennett, D. (2003). Freedom Evolves. New York: Viking. 
Derrida, J. (2016). The Animal That Therefore I Am (More to Follow) on JSTOR. Jstor.org.Retrieved 28 May 2016, from https://www.jstor.org/stable/1344276

Evans, G. \& McDowell, J. (1982). The Varieties of Reference. Oxford [Oxfordshire]: Clarendon Press.

Frankfurt, H. (1971). Freedom of the Will and the Concept of a Person. The Journal Of Philosophy,68(1), 5. http://dx.doi.org/10.2307/2024717

Heidegger, M. (1962). Being and Time. New York: Harper.

Hume, D. (1937). An Enquiry Concerning Human Understanding. Raleigh, N.C.: Alex Catalogue.

James, W. (1950). The Principles of Psychology. [New York]: Dover Publications.

Kane, R. (1996). The Significance of Free Will. New York: Oxford University Press.

Kant, I. (1956). Critique of Practical Reason. New York: Liberal Arts Press.

Kant, I. \& Meiklejohn, J. (1901). The Critique of Pure Reason. Raleigh, N.C.: Alex Catalogue.

Lévinas, E. (1969). Totality and Infinity. Pittsburgh, Pennsylvania: Duquesne University Press.

Merleau-Ponty, M. (1968). The Phenomenology of Perception. New York: Philosophical Library.

Merleau-Ponty, M. (1964). The Primacy of Perception. [Evanston, Ill.]: Northwestern University Press.

Moore, G. (1903). Principia Ethica. Cambridge: Cambridge University Press.

Norris, C. (2016). Frankfurt on Second-Order Desires and the Concept of a Person. Hrcak.srce.hr. Retrieved 28 May 2016, from http://hrcak.srce.hr/file/91379

Rovane, C. (1998). The Bounds of Agency. Princeton, N.J.: Princeton University Press.

Sartre, J. (1956). Being and Nothingness. New York: Philosophical Library.

Schopenhauer, A. \& Payne, E. (1966). The World as Will and Representation. New York: Dover Publications.

Webber, J. (2011). Reading Sartre. London: Routledge. 